\title{
Effect of light touch on body sway during a stable posture with blocked visual information
}

\author{
Jong-Gun Kim ${ }^{a}$, Jin-Hong Kim ${ }^{a}$, Kwang-Sun Do ${ }^{a}$, Jongeun Yim ${ }^{b}$ \\ ${ }^{a}$ Department of Physical Therapy, The Graduate School, Sahmyook University, Seoul, Republic of Korea \\ ${ }^{b}$ Department of Physical Therapy, College of Health and Welfare, Sahmyook University, Seoul, Republic of Korea
}

\begin{abstract}
Objective: The purpose of this study was to investigate how light touch with a finger affects balance ability when a posture is maintained in the condition of visual information blockage and to provide a fundamental material for developing balance ability in
\end{abstract} the process of rehabilitation treatment.

Design: Cross-sectional study.

Methods: The study subjects were 17 healthy men and women in their twenties and thirties who were studying at S University in Seoul. The system was comprised of an equilateral triangular force platform. Subjects were asked to step on the foot position of the force platform (Good Balance, Finland) barefooted for 30 seconds, with eyes closed, hands hanging down loosely, and feet comfortably apart. It was connected to a laptop by using Bluetooth technology. An experiment was conducted in the following three circumstances: 1) no-touch trial, 2) light touch to the back (T7 area), and 3) light touch to the middle finger of the left hand. Each subject was given a 10-minute break between consecutive measurements. The experimental circumstances were performed randomly. Anteroposterior sway (APSV), mediolateral sway velocity (MLSV), and velocity moment (VM) were measured.

Results: The APSVs (mm/s) were 9.32 \pm 3.37 and 5.45 \pm 2.98 ; the MLSVs $(\mathrm{mm} / \mathrm{s}), 6.39 \pm 3.35$ and $3.31 \pm 2.48$; and VM $\left(\mathrm{mm}^{2} / \mathrm{s}\right)$, $17.13 \pm 11.75$ and $6.76 \pm 8.31$ in the first and second experimental circumstances, respectively. APSV, MLSV, and VM values were significantly improved with the 1) no-touch trial and 2) light touch to the back trail conditions compared with the 3) light touch to the middle finger of the left hand condition $(p<0.05)$.

Conclusions: This study revealed that the balance ability for maintaining a body posture was influenced more by light touch to the back (T7) than by light touch with the sensitive fingertip and body sway diminished after visual information was blocked.

Key Words: Feedback, sensory, Touch, Postural balance

\section{Introduction}

Since the existence of humankind on earth, humans have evolved in resistance to gravity, which is an invisible but ever-present force, in order to survive on earth. Owing to gravitational action, humans are forced to use their balance ability to take a body position and maintain a posture. Recent studies have focused on how to control posture. Many complicated actions are involved in maintaining human posture in space. Reportedly, control of human posture is dependent on vision, somesthetic sensibility, and the vestibular system
[1-6]. Posture is well known to be controlled by vision. However, the effect of touch, which is part of somesthetic sensibility, on posture is yet to be clarified. Generally, when an object contacts the human body, the somesthetic sensibility system helps to correct posture and dictates the arrangement of the body depending on proprioception, pressure, and kinetic sense [7]. However, in 2006, Menz et al. [8] reported that the manual contact of the body is simply contact and friction with skin.

When people lose visual information in everyday life, leading to a swaying posture, they are able to recover and

Received: 16 August, 2016 Revised: 1 September, 2016 Accepted: 2 September, 2016

Corresponding author: Jongeun Yim

Department of Physical Therapy, College of Health and Welfare, Sahmyook University, 815 Hwarang-ro, Nowon-gu, Seoul 01795, Republic of Korea Tel: 82-2-3399-1637 Fax: 82-2-3399-1639 E-mail: yyannan@hanmail.net

(c) This is an Open-Access article distributed under the terms of the Creative Commons Attribution Non-Commercial License (http://creativecommons.org/licens es/by-nc/4.0) which permits unrestricted non-commercial use, distribution, and reproduction in any medium, provided the original work is properly cited.

Copyright $@ 2016$ Korean Academy of Physical Therapy Rehabilitation Science 
maintain the posture fast with light force by using a handrail, wall, or furniture [9]. The sensory cues acquired through locomotion to various object locations in the study were orientation free with respect to the self [10]. Therefore, how sensory touch affects recovery and maintenance of posture should be investigated.

Previous studies focused on vision and the vestibular system. However, research on somesthetic sensibility for maintaining posture is lacking. In particular, not much research has been conducted on the change in posture when light touch is applied with the tip of a figure [11].

In 1994, Holden et al. [12] reported that when light touch of $1 \mathrm{~N}$ was applied by using the index finger, postural sway at the time of maintaining posture was greatly diminished. In addition, in the research of Jeka and Lackner (1994) [13], when a patient closed the eyes and maintained posture, light touch greatly diminished the patient's postural sway. However, the region of light touch was mostly limited to the fingertip and research has rarely been conducted on the effect of contact with an insensitive body region.

Therefore, the purpose of this study was to find the effect of light touch with a finger on balance ability when one's visual information is blocked in posture maintenance and to contribute to providing a fundamental material for developing balance ability in the process of rehabilitation treatment.

\section{Methods}

\section{Subjects}

The study subjects were 17 healthy men and women in their twenties and thirties who were studying at S University in Seoul. They voluntarily agreed to participate in this experiment after receiving explanations regarding the purpose and process of this study and had no problems with neurological disabilities and balance ability. The characteristics of the study subjects are presented in Table 1.

Table 1. Characteristics of all subjects $(\mathrm{N}=17)$

\begin{tabular}{lc}
\hline \multicolumn{1}{c}{ Variable } & Subjects \\
\hline Sex & \\
Male & 12 \\
Female & 5 \\
Age $(\mathrm{y})$ & $31.47(4.96)$ \\
Height $(\mathrm{cm})$ & $169.24(6.61)$ \\
Body weight $(\mathrm{kg})$ & $69.76(13.09)$ \\
\hline
\end{tabular}

Values are presented as number only or mean (SD).

\section{Experimental protocol}

This is a cross-sectional study. In the condition where each study subject closed the eyes and stood, light touch was applied to each body region, standing is lines marked on the device and then postural sway was measured. The study subjects were asked to step on the foot position of the force platform (Good Balance, Metitur, Finland, 2008) barefoot, close their eyes, and stand still. The system was comprised of an equilateral triangular force platform. It was connected to a laptop by using Bluetooth technology. The sampling frequency was $50 \mathrm{~Hz}$. An experiment was conducted in the following three circumstances: 1) no-touch trial, 2) light touch to the back (back of central part is T7 area), and 3) light touch to the middle finger of the left hand. In the no-touch trial, the subjects were asked to close their eyes and stand still for 30 seconds (Figure 1). In the case of light touch to the back, when the subject had stood still for 30 seconds, the tester lightly touched the seventh thoracic vertebra (T7) located between the scapular inferior angle (Figure 2). In the case of light touch to a finger, when the subject had stood still for 30 seconds, the tester lightly touched the subject's middle finger (Figure 3). Each subject was given a 10-minute break between consecutive measurements. The experimental circumstances were performed randomly.

\section{Measurement}

The following three variables were calculated for the tra-

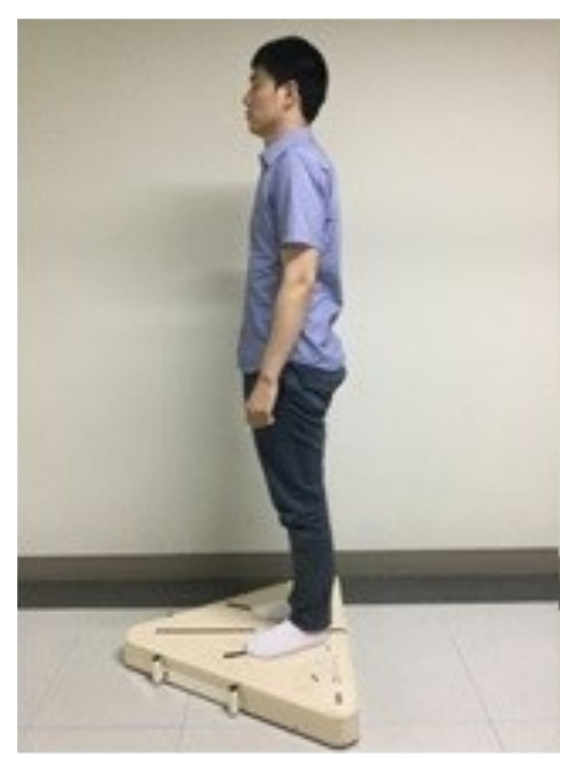

Figure 1. No touch. 
jectory of the center of pressure: anteroposterior sway velocity (APSV), mediolateral sway velocity (MLSV), and velocity moment (VM), which refers to the first moment of velocity estimated as the mean area covered by the movement of the center of pressure during each second of the test, taking into account both the distance from the geometrical midpoint of the test and the speed of the movement during the same period [14]. Standing balance measurements were performed with the subject standing on a force platform for 30 seconds, with the eyes closed, hands hanging down loosely, and feet comfortably apart. The tests were performed three times in the same order for each subject.

\section{Statistical analysis}

For the statistical analysis, SPSS Statistics ver. 17.0 (SPSS Inc., Chicago, IL, USA) was used in this study. To compare

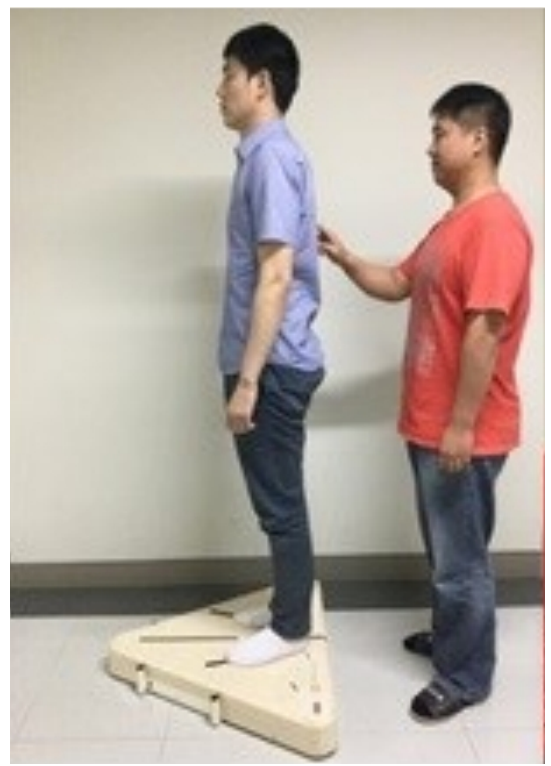

Figure 2. Touch to the back. the difference in dependent variables between the groups in each experimental method, one-way analysis of variance was conducted. As post hoc test, the Scheffe test was conducted. A statistical significance level $(\alpha)$ was 0.05 .

\section{Results}

In the condition where the eyes were closed, all the subjects experienced three circumstances ( 1 , no touch; 2 , touch to the back [around T7] with the fingertip; 3, touch to the middle finger of each subject). Under these circumstances, APSV, MLSV, and VM were measured. As a result, the APSVs $(\mathrm{mm} / \mathrm{s})$ were $9.32 \pm 3.37$ and $5.45 \pm 2.98$; the MLSVs $(\mathrm{mm} / \mathrm{s}), 6.39 \pm 3.35$ and $3.31 \pm 2.48$; and $\mathrm{VM}\left(\mathrm{mm}^{2} / \mathrm{s}\right), 17.13 \pm$ 11.75 and $6.76 \pm 8.31$ in the first and second experimental circumstances, respectively. Therefore, the values were sig-

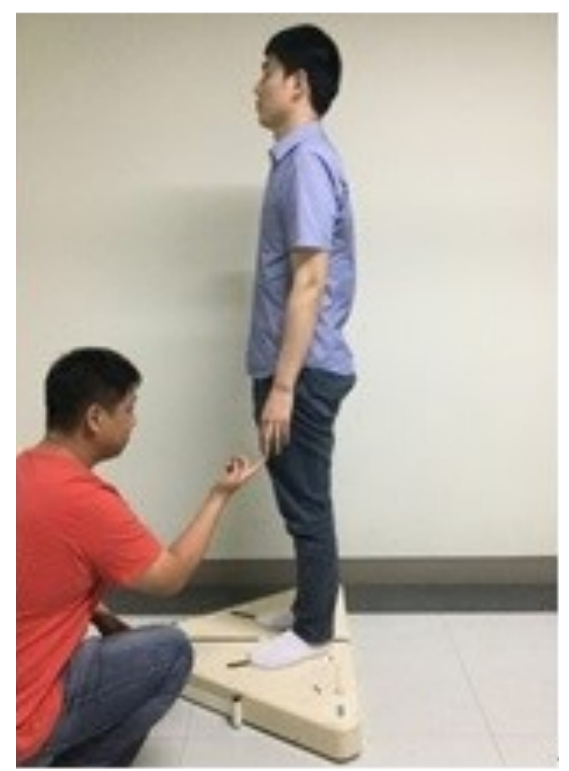

Figure 3. Touch to the finger.

Table 2. Balance difference in each experimental circumstance

$(\mathrm{N}=17)$

\begin{tabular}{|c|c|c|c|c|}
\hline Type & 1 & 2 & 3 & $F(p)$ post hoc \\
\hline $\operatorname{APSV}(\mathrm{mm} / \mathrm{s})$ & $9.32(3.37)$ & $5.45(2.98)$ & $7.67(1.58)$ & $\begin{array}{c}2(0.006) \\
12 \mid 3\end{array}$ \\
\hline $\operatorname{MLSV}(\mathrm{mm} / \mathrm{s})$ & $6.39(3.35)$ & $3.31(2.48)$ & $5.50(1.95)$ & $\begin{array}{c}2(0.001) \\
12 \mid 3\end{array}$ \\
\hline $\mathrm{VM}\left(\mathrm{mm}^{2} / \mathrm{s}\right)$ & $17.13(11.75)$ & $6.76(8.31)$ & $14.85(7.58)$ & $\begin{array}{c}2(0.009) \\
12 \mid 3\end{array}$ \\
\hline
\end{tabular}

Values are presented as mean (SD).

1: no touch, 2: touch to the back, 3: touch to the finger, APSV: anteroposterior sway velocity, MLSV: mediolateral sway velocity, VM: velocity moment. 
nificantly different $(p<0.05$; Table 2).

\section{Discussion}

In this study, when light touch was applied, balance ability changed depending on the body region. The present researchers tested the effect of light touch with a finger on the balance ability of the body in the condition where vision was blocked. With the use of the index fingertip, the tester applied light touch to the study subject's back around T7 (not sensitive) and middle fingertip (sensitive). The research of Jake et al. revealed that light finger touch applied at a constant force of $1 \mathrm{~N}$ is effective for postural sway [5,12,13,15-17]. In addition, the research of Wing et al. [18] reported that the body sway velocity caused by light touch was $176 \mathrm{~ms}$. These results are different from our study results. For faster and easier correction of posture caused by somesthetic sensibility, awareness that light touch to the sensitive fingertip causes less postural sway is necessary. However, as shown in the study result, the APSVs of light touch to the back (T7), light touch to the fingertip, and no touch were $5.45 \pm 2.98$, $7.67 \pm 1.58$, and $9.32 \pm 3.37 \mathrm{~mm} / \mathrm{s}$, respectively. Therefore, the light touch applied helped keep a more stable posture. The reason why the APSV of light touch to the back (T7) was the lowest was that the touch to the back had a directional nature compared to the touch to the fingertip. The fingertip has nothing to do with its directional nature, whereas the touch to the region around the back (T7) is in the same direction as the anterior and posterior body sway. The MLSVs of light touch to the back (T7), light touch to the fingertip, and no touch were $3.31 \pm 2.48,5.50 \pm 1.95$, and $6.39 \pm 3.35$ $\mathrm{mm} / \mathrm{s}$, respectively. This indicates that the ability of the body to assume a posture in the vestibular reflex system after visual information blockage has nothing to do with somesthetic sensibility. The back, which is less sensitive than the fingertip with many sensory nerves, supplementing postural sway in a more stable way means that the somesthetic sensibility of the trunk closer to the spine influences the arrangement of the body faster and that the somesthetic sensibility sensors relating to posture are more distributed to the trunk. The VMs of light touch to the back (T7), no touch, and light touch to the fingertip were $6.76 \pm 8.31,17.13 \pm 11.75$, and $14.85 \pm 7.58 \mathrm{~mm}^{2} / \mathrm{s}$, respectively. Compared with no touch, light touch to the back caused no postural sway. The exact mechanism of small sway in each different circumstance could not be explained because standing in a stable posture not only requires contraction of the skeletal muscle and feedback of sensory impulse but also complicates interaction between processes [19]. Many studies report that posture is related to the cortex [20-22]. In particular, posture control with the eyes closed was reported to show activation of the prefrontal cortex [23].

To objectify the degree of light touch, previous studies maintained a force of $1 \mathrm{~N}$ in a measured period by using measurement equipment [13]. However, this study provided light touch as little as each study subject was able to recognize. It was designed in the realization that supplying constant and continuous touch in the clinical environment was difficult. In the future research, touch should be applied with a more constant and regular force. Studies have been conducted on the shoulder, legs, and fingers as light touch regions of the body $[13,24,25]$. Therefore, light touch regions should be diversified, such as the front and back, and up and down, and whether body regions diminish postural sway should be investigated.

In conclusion, this study investigated how the body of normal adults sways by light touch when their visual information is blocked. Light touch to the body influenced diminished postural sway in the condition where visual information was blocked. In particular, light touch to the region around the back (T7), which is not as sensitive as the fingertip, diminished postural sway. Compared with no touch, touch to the fingertip diminished postural sway. However, no significant difference was found. Therefore, in terms of postural maintenance, touch to the region around the spine influenced postural sway more than touch to the sensitive body region. The study results will be able to guide therapists in suggesting a proper touch region for maintaining their patients' balance abilities in the rehabilitation process and to contribute to providing fundamental information for walking training.

\section{Conflict of Interest}

The authors declared no potential conflicts of interest with respect to the authorship and/or publication of this article.

\section{References}

1. Collins JJ, De Luca CJ. The effects of visual input on open-loop and closed-loop postural control mechanisms. Exp Brain Res 1995;103:151-63.

2. Dijkstra TM, Schöner G, Giese MA, Gielen CC. Frequency dependence of the action-perception cycle for postural control in a 
moving visual environment: relative phase dynamics. Biol Cybern 1994;71:489-501.

3. Horak FB, Shupert CL, Dietz V, Horstmann G. Vestibular and somatosensory contributions to responses to head and body displacements in stance. Exp Brain Res 1994;100:93-106.

4. Inglis JT, Horak FB, Shupert CL, Jones-Rycewicz C. The importance of somatosensory information in triggering and scaling automatic postural responses in humans. Exp Brain Res 1994; 101:159-64.

5. Jeka J, Oie K, Schöner G, Dijkstra T, Henson E. Position and velocity coupling of postural sway to somatosensory drive. J Neurophysiol 1998;79:1661-74.

6. van Asten WN, Gielen CC, Denier van der Gon JJ. Postural adjustments induced by simulated motion of differently structured environments. Exp Brain Res 1988;73:371-83.

7. Winter DA. Human balance and posture control during standing and walking. Gait Posture 1995;3:193-214.

8. Menz HB, Lord SR, Fitzpatrick RC. A tactile stimulus applied to the leg improves postural stability in young, old and neuropathic subjects. Neurosci Lett 2006;406:23-6.

9. Johannsen L, Lou SZ, Chen HY. Effects and after-effects of voluntary intermittent light finger touch on body sway. Gait Posture 2014;40:575-80

10. Gieser DK, Goldberg MF, Apple DJ, Hamming NA, Kottow MH. Persistent hyperplastic primary vitreous in an adult: case report with fluorescein angiographic findings. J Pediatr Ophthalmol Strabismus 1978;15:213-8.

11. Jeka JJ. Light touch contact as a balance aid. Phys Ther 1997; 77:476-87.

12. Holden M, Ventura J, Lackner JR. Stabilization of posture by precision contact of the index finger. J Vestibul Res 1994;4: 285-301.

13. Jeka JJ, Lackner JR. Fingertip contact influences human postural control. Exp Brain Res 1994;100:495-502.

14. Salminen M, Vahlberg T, Sihvonen S, Sjösten N, Piirtola M, Isoaho $\mathrm{R}$, et al. Effects of risk-based multifactorial fall prevention on postural balance in the community-dwelling aged: a randomized controlled trial. Arch Gerontol Geriatr 2009;48:22-7.

15. Jeka JJ, Lackner JR. The role of haptic cues from rough and slippery surfaces in human postural control. Exp Brain Res 1995; 103:267-76.

16. Lackner JR, DiZio P, Jeka J, Horak F, Krebs D, Rabin E. Precision contact of the fingertip reduces postural sway of individuals with bilateral vestibular loss. Exp Brain Res 1999;126: 459-66.

17. Jeka JJ, Easton RD, Bentzen BL, Lackner JR. Haptic cues for orientation and postural control in sighted and blind individuals. Percept Psychophys 1996;58:409-23.

18. Wing AM, Johannsen L, Endo S. Light touch for balance: influence of a time-varying external driving signal. Philos Trans R Soc Lond B Biol Sci 2011;366:3133-41.

19. Slobounov S, Hallett M, Cao C, Newell K. Modulation of cortical activity as a result of voluntary postural sway direction: an EEG study. Neurosci Lett 2008;442:309-13.

20. Mochizuki G, Boe S, Marlin A, McIlRoy WE. Perturbationevoked cortical activity reflects both the context and consequence of postural instability. Neuroscience 2010;170:599-609.

21. Jacobs JV, Horak FB. Cortical control of postural responses. J Neural Transm (Vienna) 2007;114:1339-48.

22. Nashner LM, Shupert CL, Horak FB. Head-trunk movement coordination in the standing posture. Prog Brain Res 1988;76:24351.

23. Ouchi Y, Okada H, Yoshikawa E, Nobezawa S, Futatsubashi M. Brain activation during maintenance of standing postures in humans. Brain 1999;122:329-38.

24. Krishnamoorthy V, Slijper H, Latash ML. Effects of different types of light touch on postural sway. Exp Brain Res 2002;147: 71-9.

25. Rogers MW, Wardman DL, Lord SR, Fitzpatrick RC. Passive tactile sensory input improves stability during standing. Exp Brain Res 2001;136:514-22. 